Tohoku J. exp. Med., 1976, 119, 211-221

\title{
Preventive Procedure of Dysuria after Radical Hysterectomy by Adnexal Flap Fixation to the Bladder
}

\author{
Ryuji Yamaguchi, Yoshio Nishikawa, Satoru Tsubomoto, \\ Katsuruki Ueha, Yoshifumi Tomit, Aktra Nakanishi and \\ Tомоко AIzawa
}

Department of Obstetrics and Gynecology, Nara Medical University, Kashihara

\begin{abstract}
Yamaguchi, R., Nishikawa, Y., Tsubomoto, S., Ueha, K., Tomit, Y., Nakanisht, A. and AIzawa, T. Preventive Procedure of Dysuria after Radical Hysterectomy by Adnexal Flap Fixation to the Bladder. Tohoku J. exp. Med., 1976, 119 (3), 211-221 - To prevent postoperative dysuria, which occurs inevitably after the radical hysterectomy, several surgical procedures have been tried. The principal method is to suture adnexal flaps to the bladder trigone and fundus. Of four procedures so far tried sequentially, the best one was to fix the bladder trigone and to support it with round ligament flaps sutured with the bladder fundus covered by tubal flaps (Type IV). In follow-up studies, Type IV proved more preferable than the other three types or the non-sutured control group in regard to the following aspects: (1) days necessary for the disappearance of residual urine, (2) appearance of urinary sensation, (3) acquirement of urinary sensation, (4) incidence of urinary incontinence, (5) residual urine/bladder capacity ratio, (6) cystometrie findings, and others. Effectiveness of our procedures, particularly of Type IV, may be ascribed to the supported bladder trigone and fundus by sutured tissues and to the acquirement of urinary sensation, rather than to the restoration of nervous contact between the bladder and the micturition center in the spinal cord.

neurogenic bladder; cervical cancer
\end{abstract}

Bladder paralysis that follows the radical hysterectomy for the cervical cancer has long plagued the patients. The preservation of the pelvic nerve (Kobayashi 1963; Matsuzawa 1967) as a supplementary procedure to prevent this fault still leaves problems in cases of Stage II of the cervical cancer. We have recently developed preventive procedures without pelvic nerve preservation. Favorable results have been obtained in clinical application of the procedures. This report describes the outline of the procedures and the results of a follow-up study.

\section{Materials}

Newly developed procedures were applied to 33 of 47 cases which underwent the radical hysterectomy (Kobayashi's modification of Okabayashi's method) during the period from May 1974 to August 1975 at the Department of Obstetrics and Gynecology, Nara Medical University Hospital. In cutting the cardinal ligament, the pelvic nerve preservation was not applied in any case of the 33 cases. Used as control were 52 cases with clear records of

Received for publication, December 27, 1975. 
residual urine or other urinary problems out of 157 patients subjected to the radical hysterectomy from 1969 to 1974.

\section{Types of Surgical Procedure}

The principal procedures are that, at the time of the radical hysterectomy, the suspended bladder trigone and fundus are given a bolster with spared round ligaments and fallopian tubes to cover them, preventing them against descending due to bladder paralysis and lack of the uterus. Our device was classified into the following four types according to the way of fixation of adnexal flap to the bladder (Fig. 1).

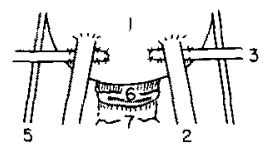

(I)

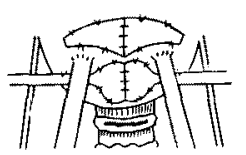

$(\nabla-a)$

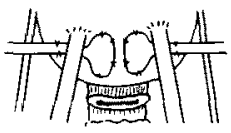

(II)

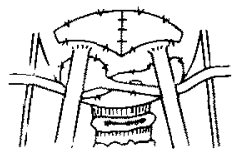

$(T-b)$

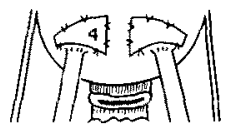

(III)

Fig. 1. Methods and procedures of adnexal flap fixation to the bladder. 1, bladder; 2, ureter; 3, round ligament; 4, fallopian tube; 5, lateral umbilical ligament; 6, vaginal stump; 7 , rectum.

Type I. After removal of the uterus, the ends of both round ligaments of the pelvic wall side, which were cut off according to the routine method of hysterectomy, are sutured with cutgut to the bladder wall of the same side around the uretero-vesical junction. This method was applied only in the initial two cases.

Type II. At the beginning of operation, the bilateral round ligaments each with a piece of thumb-nail-sized uterine muscle flap are cut apart. After removal of the uterus, the spared round ligament flaps are sutured to the same-side bladder wall around the dorsal portion of uretero-vesical junction (6 cases).

Type III. At the beginning of operation, the fallopian tubes are cut near the isthmoampullar part and let remain with the infundibulo-pelvic ligaments and the mesosalpinces. After removal of the uterus, the spared fallopian tubes are opened on the dorsal side (the opposite side of the mesosalpinx) to make an ampullar open-flap; the mucous surface, seratched to cause a slight bleeding, are sutured to the bladder wall around the same-side uretero-vesical junction (6 cases).

Type IV. (A) Bilateral round ligament flaps are passed under the ureter of the respective side. These flaps are sutured end-to-end and fixed to the bladder trigone. Then, the fallopian tube flaps made in the same manner as described in Type III are sutured to the fundie wall of the bladder to cover and support it (6 cases). (B) The round ligament flaps are led to pass under the ureter of the respective side and sutured to the bladder wall of the opposite side at the dorsal portion of uretero-vesical junction, and then fallopian tube flaps are sutured to the fundic wall of the bladder as in the way shown in Type IV-A (6 cases). (C) The round ligament flaps are led to pass under the lateral umbilical ligaments of the same side, sutured side-to-side each other, and fixed to the bladder trigone. Tubal flap fixation is made in the same way as shown in Type IV-A 
and -B ( 7 cases, follow-up period within 4 months). With Type IV, the bladder trigone and fundus become to be covered and supported by the flaps of the round ligament and fallopian tubes.

In all cases including control, the ureter was held within the peritoneal cavity according to the proposal of Novak (1956) and Endo and Okabe (1964) to prevent it against urinary fistula. Para-coceygeal drainage was applied following Kobayashi's method. None of antibiotics or anti-cancer drugs were administered to the parametrial dead space. In postoperative care, no specific treatments were made except general chemotherapy. The para-coccygeal drain was removed three days after operation. An intra-vesical indwelling catheter was placed through the urethra, usually for seven days after operation. After removal of the indwelling cathether, a spontaneous voiding training was practiced. To the cases in difficulty in spontaneous urination, urethral dilation was led with the administration of vitamin $\mathrm{B}_{1}$ or distigmine bromide (Ubretid). These postoperative treatments were almost similar in 33 cases and the control group.

\section{Follow-ur Study}

The effectiveness of our procedures was evaluated by checking days took for disappearance of residual urine (expressed by days after the operation up to the last day of three consecutive days when averaged one-time residual urine decreased less than $50 \mathrm{ml}$ ), the residual urine ratio (residual urine volume/bladder capacity $\times 100=\%$ ), presence or absence of urinary sensation and the day of its onset, incontinence, and other urinary complaints. The methods used for examining the bladder function or the state of the bladder were cystoscopy, intravenous pyelography, retrograde cystography, cystometry (Lewis's apparatus), and urinary bacterial examination. These examinations were carried out before and after operation. The periods of observation were 13 months at longest.

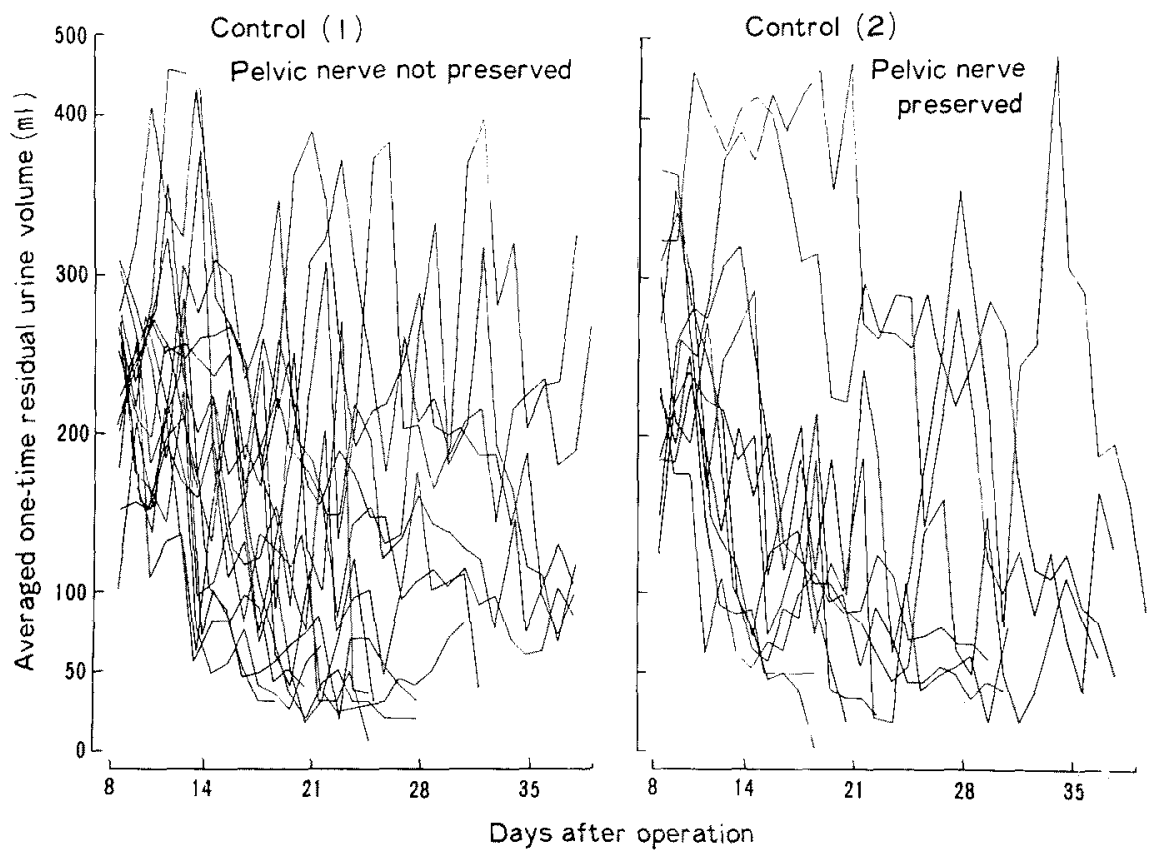

Fig. 2. Postoperative courses of residual urine in control group. Averaged one-time residual volume in $\mathrm{ml}$. 


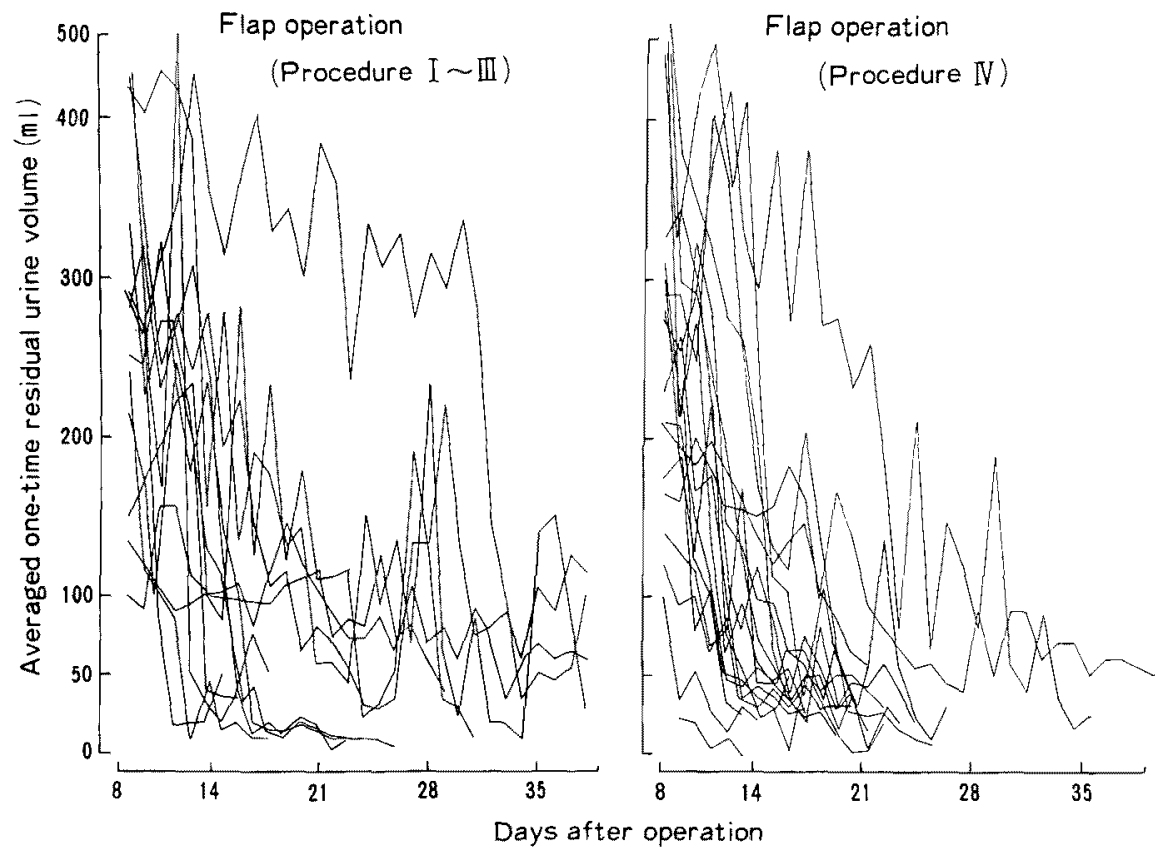

Fig. 3. Postoperative courses of residual urine in flap operation group. Averaged one-time residual urine volume in $\mathrm{ml}$.

TABLE 1. Results of adnexal

\begin{tabular}{|c|c|c|c|c|}
\hline & & \multirow{2}{*}{$\begin{array}{c}\text { Control } 1 \\
(n=52, \text { post-op. } \\
2-6 \text { yrs. }\end{array}$} & & Flap operation \\
\hline & & & $\begin{array}{c}I \\
(n=2)\end{array}$ & $\begin{array}{c}\text { II } \\
(n=6)\end{array}$ \\
\hline \multirow{2}{*}{\multicolumn{2}{|c|}{$\begin{array}{l}\text { Appearance of urinary sens- } \\
\text { ation (post-op. days) }\end{array}$}} & \multirow{2}{*}{-} & 19.5 & $60.2 \pm 53.2$ \\
\hline & & & & $37.6 \pm 38.9$ (4) \\
\hline \multirow{2}{*}{\multicolumn{2}{|c|}{$\begin{array}{l}\text { Residual urine less than } 50 \\
\text { ml (post-op. days) }\end{array}$}} & \multirow{2}{*}{$33.7 \pm 17.6$} & 24.0 & $27.8 \pm 10.1$ \\
\hline & & & & $25.3 \pm 10.0$ (4) \\
\hline \multirow{8}{*}{ 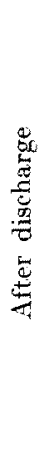 } & \multirow{2}{*}{$\begin{array}{l}\text { Residual urine volume } \\
(\mathrm{ml})\end{array}$} & \multirow{2}{*}{$70.4 \pm 77.2$} & 17.0 & $35.5 \pm 27.8$ \\
\hline & & & & $32.9 \pm 29.4$ (4) \\
\hline & \multirow{2}{*}{$\begin{array}{l}\text { Residual urine ratio } \\
\qquad(\%)\end{array}$} & \multirow{2}{*}{$19.8 \pm 23.3$} & 3.7 & $7.7 \pm 5.6$ \\
\hline & & & & $7.0 \pm 5.8(4)$ \\
\hline & \multirow{2}{*}{$\begin{array}{c}\text { Urinary sensation }(+) \\
(\%)\end{array}$} & \multirow{2}{*}{$15 / 52(28.8)$} & $1 / 2(50.0)$ & $5 / 6(83.3)$ \\
\hline & & & & $9 / 14(64.2)$ (4) \\
\hline & \multirow{2}{*}{$\begin{array}{c}\text { Incontinence }(+) \\
\qquad(\%)\end{array}$} & \multirow{2}{*}{$40 / 52(76.9)$} & $0 / 2(0.0)$ & $3 / 6(50.0)$ \\
\hline & & & & $6 / 14(42.8)$ \\
\hline
\end{tabular}




\section{RESULTS}

The results in 26 cases which were followed up over six months are summarized in Tables 1-3 and Figs. 2 and 3. Data of seven cases in Type IV-C were listed up only in Table $I$ and Fig. 3 because their observation periods were not yet sufficient (less than four months). Many of cases began to void spontaneously within one week after the removal of indwelling catheter, and residual urine reduced to less than $50 \mathrm{ml}$ in 21.4 days, on the average, after the operation. Urinary sensation occurred during hosptial days in 28 of 33 cases. All cases treated with Type IV restored urinary sensation in 15.9 days on the average.

Of 25 cases undergoing pre- and postoperative cystometry, all had a "high pressure type" from one to three months after operation, but at six months and later some approached the "normal pressure type", especially nine of 12 cases in Type IV-A and -B showed the "normal pressure" cystometrogram (Tables 2 and 3, Figs. 4 and 5). Retrograde cystography revealed almost absent or slight deformations. The bladder neck and fundus were well prevented from descending. In Type IV, there was no case of "pine tree" bladder or vesico-ureteral reflux (VUR).

The most favorable results were obtained in cases of Type IV. The followup data of Type IV-A and -B were shown in Table 4.

\begin{tabular}{|c|c|c|c|}
\hline \multicolumn{3}{|l|}{$(n=26)$} & \multirow{2}{*}{$\begin{array}{l}\text { Significance } \\
\text { at } a=0.05\end{array}$} \\
\hline $\begin{array}{c}\mathrm{III} \\
(n==6)\end{array}$ & $\begin{array}{r}\text { IV }(\mathrm{A} \& \mathrm{~B}) \\
(n=12)\end{array}$ & $\begin{array}{l}\text { Total of } \\
\text { I IV } 9\end{array}$ & \\
\hline $22.9 \pm 13.9$ & $\begin{array}{c}18.9 \pm 19.5 \\
(15.9 \pm 5.8)^{*}\end{array}$ & $28.8 \pm 31.6$ & (2):(4) (-) \\
\hline $23.3 \pm 22.0$ & $\begin{array}{c}16.9 \pm 4.5 \\
(18.0 \pm 4.7)^{*}\end{array}$ & $21.4 \pm 8.9$ & $\begin{array}{l}\text { (1):(2) }(+) \\
\text { (1):(3) }(+) \\
\text { (2):(4) }(+)\end{array}$ \\
\hline $32.7 \pm 35.1$ & $20.0 \pm 18.4$ & $26.5 \pm 25.3$ & $\begin{array}{l}\text { (1):(2) }(+) \\
\text { (1):(3) }(+) \\
\text { (2):(4) }(-)\end{array}$ \\
\hline $6.7 \pm 6.7$ & 4. $7 \pm 5.4$ & $5.9 \pm 5.7$ & $\begin{array}{l}\text { (1):(2) }(+1 \\
\text { (1):(3) }(+) \\
\text { (2):(4) }(-)\end{array}$ \\
\hline $3 / 6(50.0)$ & $12 / 12(100.0)$ & $21 / 26(80.7)$ & $\begin{array}{l}\text { (1):(2) }(+) \\
\text { (1):(3) }(+) \\
\text { (2):(4) }(+)\end{array}$ \\
\hline $3 / 6(50.0)$ & $1 / 12(8.3)$ & $7 / 26(26.9)$ & $\begin{array}{l}\text { (1):(2) }(+) \\
\text { (1):(3) }(+) \\
\text { (2):(4) }(+)\end{array}$ \\
\hline
\end{tabular}

IV.C are included. 
TaBle 2. Postoperative cystometry (1). Transition of final pressure (mmHg)

\begin{tabular}{|c|c|c|c|c|c|c|}
\hline & & Before & & After & peration & \\
\hline & & operation & $<3$ months & $<6$ months & $>12$ months & $>1$ year \\
\hline & $\begin{array}{l}\text { Nerve not pre- } \\
\text { served }(n=26)\end{array}$ & - & - & $\cdots$ & - & $\begin{array}{c}23.5 \pm 13.0(1) \\
(n=26)\end{array}$ \\
\hline $\begin{array}{l}\text { Control } \\
(n=39)\end{array}$ & $\begin{array}{l}\text { Nerve pre- } \\
\text { served }(n=13)\end{array}$ & - & 一 & - & - & $\begin{array}{c}22.2 \pm 11.2(2) \\
(n=13)\end{array}$ \\
\hline & Total & - & - & 一 & 一 & $\begin{array}{c}25.0 \pm 12.4(3) \\
(n=39)\end{array}$ \\
\hline & $\begin{array}{l}\mathrm{I} \sim \mathrm{III} \\
\quad(n=13)\end{array}$ & $\begin{array}{c}7.2 \pm 4.2 \\
(n=5)\end{array}$ & $\begin{array}{c}24.2 \pm 16.24) \\
(n=8)\end{array}$ & $\begin{array}{c}20.6 \pm 12.0(7) \\
(n=10)\end{array}$ & $\begin{array}{c}18.4 \pm 15.2(10) \\
(n=5)\end{array}$ & - \\
\hline $\begin{array}{l}\text { Flap op. } \\
(n=24)\end{array}$ & $\underset{(n=11)}{\mathrm{IV}(\mathrm{A} \& \mathrm{~B})}$ & $\begin{array}{r}11.0 \pm 2.6 \\
(n=10)\end{array}$ & $\begin{array}{c}37.7 \pm 8.3(5) \\
(n=12)\end{array}$ & $\begin{array}{c}11.5 \pm 8.0(8) \\
(n=11)\end{array}$ & - & - \\
\hline & Total & $\begin{array}{r}9.7 \pm 3.6 \\
(n=15)\end{array}$ & $\begin{array}{c}33.5 \pm 13.56 \\
(n=20)\end{array}$ & $\begin{array}{c}15.8 \pm 10.99 \\
(n=21)\end{array}$ & $\ldots$ & - \\
\hline Sigr & ificancy at $a=0$. & $\begin{array}{l}1: 8 \\
1: 9 \\
1: 10\end{array}$ & $\begin{array}{l}+1 \\
+1 \\
+)(a=0.1)\end{array}$ & $\begin{array}{l}8(+) \\
9(t) \\
9(t)\end{array}$ & $\begin{array}{ll}3: 9 & (+) \\
4: 5 & (+) \\
5: 8 & (+)\end{array}$ & $\begin{array}{l}6: 9(+) \\
7: 8(+)\end{array}$ \\
\hline
\end{tabular}

Note: Data of Type IV.C were excluded.

TABLE 3. Postoperative cystometry (2). Incidence of high pressure bladder

\begin{tabular}{|c|c|c|c|c|c|c|}
\hline & & \multicolumn{5}{|c|}{ Final pressure (mmHg) } \\
\hline & & $<10$ & $<15$ & $<20$ & $<30$ & $>31$ \\
\hline \multirow{6}{*}{$\begin{array}{l}\text { Control } \\
(n=39)\end{array}$} & \multirow{2}{*}{$\begin{array}{l}\text { Nerve not pre- } \\
\text { served }(n=26)\end{array}$} & $3(11.5 \%)$ & $4(15.3 \%)$ & \multirow{2}{*}{$4(15.3 \%)$} & \multirow{2}{*}{$4(15.396)$} & \multirow{2}{*}{$11(42.396)(9)$} \\
\hline & & \multicolumn{2}{|c|}{$7(17.9 \%)(1)$} & & & \\
\hline & \multirow{2}{*}{$\begin{array}{l}\text { Nerve pre- } \\
\text { served }(n=13)\end{array}$} & $2(15.3)$ & $2(15.3)$ & \multirow{2}{*}{$2(15.3)$} & \multirow{2}{*}{$3(23.0)$} & \multirow[b]{2}{*}{$4(30.7)$} \\
\hline & & $4(30.7)$ & (2) & & & \\
\hline & \multirow{2}{*}{ Total } & $5(12.8)$ & $6(15.3)$ & \multirow{2}{*}{$6(15.3)$} & \multirow{2}{*}{$7(17.9)$} & \multirow{2}{*}{$15(38.4)$} \\
\hline & & $11(28.2)$ & (3) & & & \\
\hline \multirow{6}{*}{$\begin{array}{l}\text { Flap op } \\
(n=24)\end{array}$} & \multirow{2}{*}{$\underset{(n=13)}{\mathrm{I} \sim \mathrm{III}}$} & $4(30.7)(4)$ & $3(23,0)$ & \multirow{2}{*}{$1(8.3)$} & \multirow{2}{*}{$2(16.6)$} & \multirow{2}{*}{$3(23.0)$} \\
\hline & & $7(53.8)$ & (5) & & & \\
\hline & \multirow{2}{*}{$\underset{(n=11)}{\operatorname{IV}(A \& B)}$} & $9(81.8)(6)$ & $0(0.0)$ & \multirow{2}{*}{$2(18.2)$} & \multirow{2}{*}{$0(0.0)$} & \multirow{2}{*}{$0(0.0)$} \\
\hline & & $9(81.8)$ & (7) & & & \\
\hline & \multirow{2}{*}{ Total } & $13(54.1)$ & $3(12.5)$ & \multirow{2}{*}{$3(12.5)$} & \multirow{2}{*}{$2(8.3)$} & \multirow[b]{2}{*}{$3(12.5)$ (12) } \\
\hline & & $16(66.6)$ & (8) & & & \\
\hline \multicolumn{2}{|c|}{ Significancy at $a=0$. } & $\begin{array}{l}1: 5(+) \\
1: 7(+) \\
1: 8(+) \\
3: 8(+)\end{array}$ & $\begin{array}{l}2: 7 \\
2: 8 \\
3: 5 \\
3: 7\end{array}$ & $(a=0.1)$ & $\begin{array}{c}4: 6(+) \\
9: 12(+) \\
10: 12(+) \\
11: 12(+)\end{array}$ & \\
\hline
\end{tabular}

Notes: (1) In flap operation group, the final pressure of the last cystometry during observation period $(6 \sim 12$ months) was used.

(2) Data of Type IV.C were excluded. 
Fig. 4. Cystometrograms before and after operation (1). Mrs. Y. S., 38 years. (Case 8 in Table 4, cervical cancer stage Ia, Procedure IV-B). Cystometric diagnosis are: normal (upper); normotonic, slightly autonomous type (middle); and almost normal type (bottom), respectively. Md: medium sensation to void (=first desire to void, or $\mathrm{FDV}$ ). $\mathrm{Mx}_{\mathrm{l}}$ : maximum sensation to void $(=\operatorname{maxi}$ mum desire to void, or MDV). $\quad \mathrm{Mx}_{2}$ : maximum bladder capacity. MVP: maximum voluntary pressure.
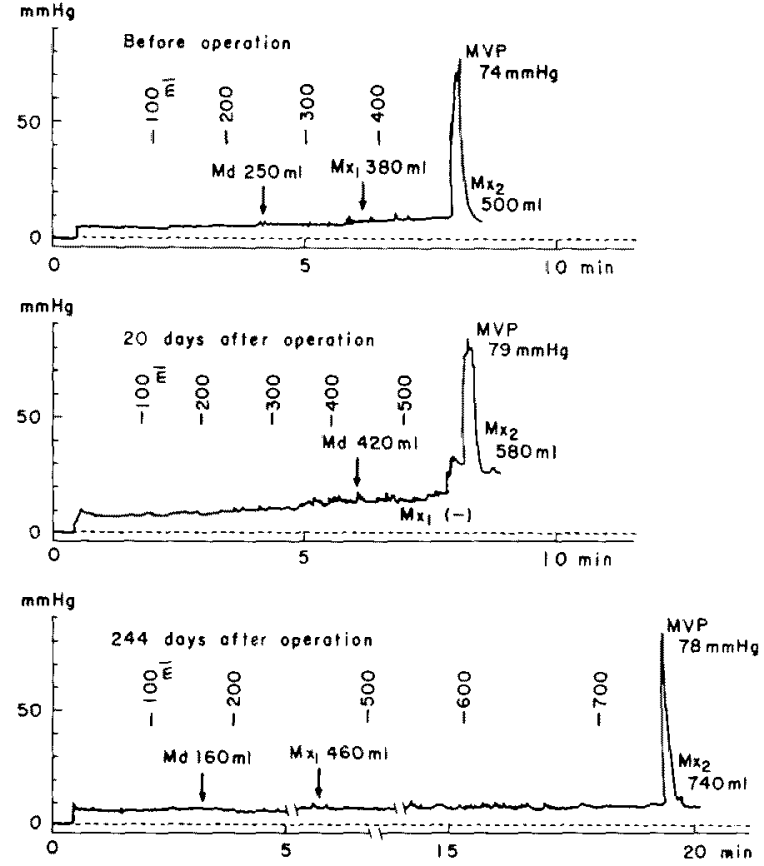
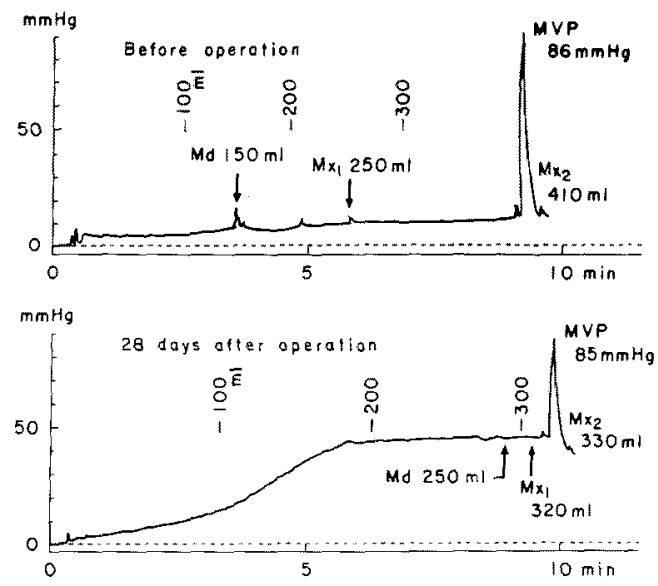

Fig. 5. Cystometrograms before and after operation (2). Mrs. O. H., 53 years. (Case 12 in Table 4, eervical cancer stage $\mathrm{Ib}$, Procedure $\mathrm{IV}-\mathrm{B}$ ). Cystometric diagnosis are: normal (upper); normotonic, partly high pressure type (middle); and almost normal type (bottom), respectively.

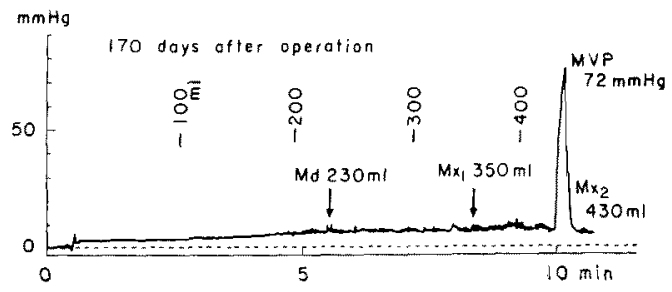


TABLE 4. Results of

\begin{tabular}{|c|c|c|c|c|c|}
\hline \multirow[t]{2}{*}{ Case } & \multirow{2}{*}{$\begin{array}{l}\text { Appearance of } \\
\text { urinary sens- } \\
\text { ation } \\
\text { (post-op. days) }\end{array}$} & \multirow{2}{*}{$\begin{array}{l}\text { Residual urine } \\
\text { less than } 50 \\
\mathrm{ml} \\
\text { (post-op. days) }\end{array}$} & \multicolumn{2}{|c|}{$\begin{array}{l}\text { Residual urine }(\mathrm{ml}) \\
\text { (Residual urine ratio \%) }\end{array}$} & \multirow[b]{2}{*}{$<9$} \\
\hline & & & $<3 \mathrm{mo}$ & $<6$ & \\
\hline 1 & 13 & 15 & $28.3(6.5)$ & $15.0(3.0)$ & $11.0(2.5\rangle$ \\
\hline 2 & 9 & 13 & $15.7(3.9)$ & $11(2.7)$ & $18(3.3)$ \\
\hline 3 & 80 & 17 & $20 \quad(3.2)$ & $6.5(1.5)$ & $0 \quad(0.0)$ \\
\hline 4 & 11 & 19 & $30 \quad(6.5)$ & & \\
\hline 5 & 13 & 22 & $19.3(4.0)$ & $26(5.4)$ & \\
\hline 6 & 21 & 18 & $34 \quad(7.2)$ & $14.5(3.0)$ & \\
\hline 7 & 14 & 15 & $14.0(2.6)$ & $34.0(6.5)$ & $20 \quad(4.0)$ \\
\hline 8 & 15 & 17 & $31.0(5.3)$ & $12.0(2.1)$ & \\
\hline 9 & 9 & 10 & $11.0(3.4)$ & $0 \quad(0.0)$ & \\
\hline 10 & 13 & 26 & $55.0(19.6)$ & $28 \quad(9.3)$ & \\
\hline 11 & 13 & 11 & $15 \quad(3.4)$ & $44 \quad(8.8)$ & \\
\hline 12 & 17 & 20 & $20 \quad(6.0)$ & $0 \quad(0.0)$ & \\
\hline \multirow{2}{*}{$\begin{array}{l}\text { Mean } \\
\pm \text { s.o. }\end{array}$} & $18.9 \pm 19.5$ & $16.9 \pm 4.5$ & $\begin{array}{l}23.7 \pm 20.7 \\
(5.9 \pm 6.6)\end{array}$ & $\begin{array}{l}17.0 \pm 16.4 \\
(3.6 \pm 3.5) \\
\end{array}$ & $\begin{array}{l}12.0 \pm 8.1 \\
(1.7 \pm 2.4)\end{array}$ \\
\hline & $*(13.3 \pm 3.4)$ & & \multicolumn{3}{|c|}{$20.0 \pm 18.4(4.7 \pm 5.4)$} \\
\hline
\end{tabular}

\section{Discussion}

Since its introduction of radical hysterectomy, Okabayashi's method has greatly improved the result in treatment of the cervical cancer. However, complete cutting off the cardinal ligaments together with underrunning pelvic nerves inevitably causes bladder paralysis after the operation. Formerly, such bladder paralysis used to be ignored with as compensation for rescue from "death with cancer". On the other hand, the urinary troubles after radical hysterectomy are considerably high in incidence. Deaths from renal insufficiency - not from cancer - as a result of chronic or repeated infection of the urinary tracts based on bladder paralysis, are not extremely rare.

In an attempt to get rid of bladder paralysis after radical hysterectomy, Kobayashi (1963) and Matsuzawa (1967) have developed a supplementary procedure with pelvic nerve preservation. And to make easy the application of this procedure, Igarashi et al. (1973) and Ueda et al. (1974) devised a nerve staining method. The pelvic nerve preservation method, however, still leaves some difficulties in performance of operation, and in cases of Stage II, the method may fail to eradicate cancer. Leveling these disadvantages, our procedures, simple in 
Type IV.A and $B$

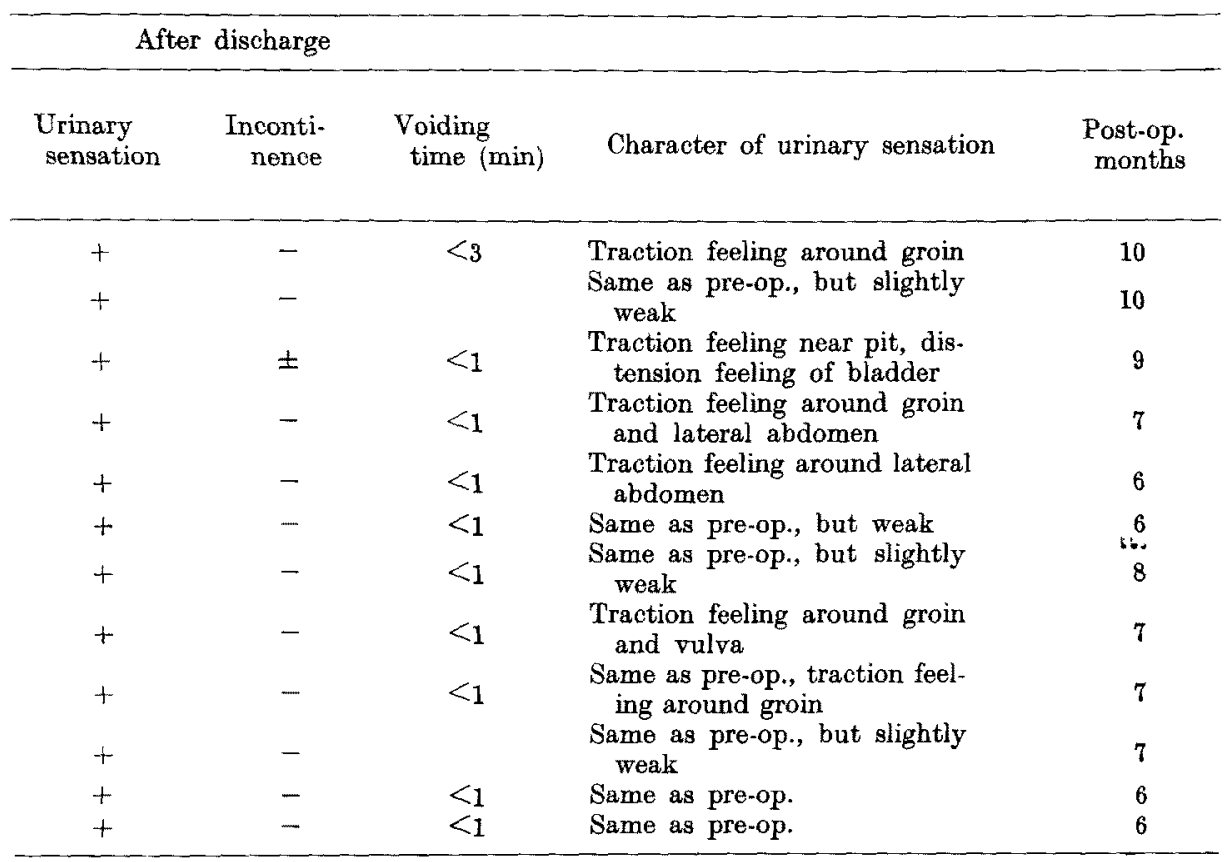

Cases 1-6: Procedure A. Cases 7-12: Procedure B.

management and without interference with radicality of operation, is of significance in the treatment of cervical cancer.

The effectiveness of our procedures in maintaining urination function following radical hysterectomy may be explained as follows: (1) the nerve endings or ganglions in the bladder wall may be re-connected with the nerves of the sutured tissues; (2) the bladder neck which is most vulnerable to a rise in intravesical pressure is substantially supported, and the bladder fundus is prevented from descending; (3) various stimuli caused by bladder filling on the muscle tissues sutured to the bladder lead to urinary sensation (so-called compensatory urinary sensation). As for (1), relevant reports in the literature suggest that the possibility is scanty. In fact, many of our cases in their postoperative cystometric curves showed a "autonomous" or "high pressure" type traceable to the pelvic nerve blocking. As to (2), the bladder support, the effect is plausibly positive, as hinted by the reported effects of sling operation for stress incontinence and bladder neck plasty for dysuria after radical hysterectomy (Imabayashi et al. 1973). Our Type IV, bolstering the bladder neck and fundus largest in area, produced the most favorable results. As for (3), the stimulation of urinary sensation, the 
effects are also plausible. Referable thereto is the report of Nakaarai et al. (1974) on a case with the bladder fixed by an ileal flap. The reporters are inclined to deny the reactivation of nerve through the ileal flap to the bladder but favor a stimulus extending to the sutured ileal flap, bringing about a kind of compensatory urinary sensation leading to pertinent urination. But to this view, Shishito and Imabayashi (1975) hold a negative stand based on their experience (their personal communication). Any hypothesis on this issue needs further confirmation.

Whatever the theoretical grounds of the effects, it is of deep interest that not a small proportion of our cases acquired urinary sensation after undergoing radical hysterectomy. Some patients expressed urinary sensation indistinguishable before and after operation, suggesting that the physiology of urination mechanism may be not so simple as described in conventional text book. On the other hand, a vague urinary sensation, expressed by some of our patients, loosely diffuse around groin, vulva, or lateral abdomen may be suggestive of the influence of the anatomical situation of the sutured tissue to the bladder.

The advantages of our procedures lie in their little interference with the radicality of operation as well as in their simple but effective means for prevention of postoperative dysuria. Countable as their flaws are an excess trouble for flap fixation procedure, and relatively larger oozing from the tissue flaps. Nevertheless, the procedures, safe and simple, may well be recommended as a favorable supplement to radical hysterectomy for the uterine cancer.

\section{Acknowledgment}

We wish to extend our thanks to Professor Emeritus Dr. Sentaro Shishito and Dr. Kenichi Imabayashi, Department of Urology, Tohoku University School of Medicine, Professor Dr. Kiichi Suzuki, Department of Urology, Yamagata University School of Medicine, and Prof. Eigoro Okajima, Department of Urology, Nara Medical University, for their kind advice in this study.

\section{References}

1) Endo, K. \& Okabe, S. (1964) Causes of uretero-vaginal fistulas after radical hysterectomy of cervical cancer. Prevention by intraperitoneal dislocation of ureter. San-Fujinka Chiryo (Jap.), 8, 28-39.

2) Igarashi, M., Hirono, M., Yanagida, C., Owada, N. \& Taguchi, A. (1973) Effects of pelvic nerve preservation by vital staining in radical hysterectomy of eervical cancer. Nippon Sanka-Fujinka Gakkai Zasshi (Jap.), 25, 1249-1250.

3) Imabayashi, K., Amano, S., Onuma, T. \& Kato, M. (1973) Bladder neck plasty: Especially on the indication of bladder neck plication and V.Y plasty for the urinary retention of neurogenic bladder with peripheral nerve injury. Rinsho Hinyokika (Jap.), 27, $407-413$.

4) Kobayashi, T. (1963) Abdominal Radical Hysterectomy with Pelvic Lymphadenectomy for Cancer of the Cervix. Nanzando Co., Tokyo.

5) Matsuzawa, M. (1967) The significance of preservation of the sacral parasympathetic nerves ( $N$. pelvicus) in the radical hysterectomy for cancer of the cervix. Nippon Sanka-Fujinka Gakkai Zasshi (Jap.), 19, 1479-1488.

6) Nakaarai, K., Ohta, K. \& Sato, Y. (1974) Sero-muscular ileal flap fixation to the bladder on neurogenic bladder: A new procedure for recovery of urinary sensation. Hinyokika Kiyo (Jap.), 20, 571-575. 
7) Novak, F. (1956) Procedure for the reduction of the number of uretero-vaginal fistulas after Wertheim's operation. Amer. J. Obstet. Gynec., 72, 506-510.

8) Ueda, K., Matsuda, A., Kaibara, M. \& Yasui, H. (1974) Staining of the pelvic nerves in radical hysterectomy of the cervical cancer. Rinsho Fujinka-Sanka (Jap.), $28,161-163$. 